\title{
Isolated bilateral macrodontia of mandibular second premolars: A case report
}

\author{
Ebru Canoglu' \\ Harun Canoglu² \\ Alper $\mathrm{Aktas}^{3}$ \\ Zafer C. Cehreli'
}

\begin{abstract}
Isolated bilateral macrodontia of mandibular second premolars is an extremely rare dental anomaly with only 5 cases reported to date. This case report presents clinical and radiographic findings of isolated bilateral macrodontia in a 12-year-old child. The patient was referred to the clinic with local crowding of mandibular posterior teeth. Radiographic findings revealed the presence of impacted macrodont mandibular second premolars and their distinct morphological appearance, characterized by large, multitubercular, molariform crowns, and tapering, single roots. Following surgical removal of the impacted premolars, orthodontic therapy was initiated to correct the malocclusion. Along with the features and treatment of this rare anomaly, this case report also illustrates the benefits, in terms of treatment planning and surgical technique, of supplementing conventional radiography with cone-beam computed tomography to localize the macrodont premolars and accurately establish their relationship with the neighboring roots and anatomic structures. (Eur J Dent 2012;6:330-334)
\end{abstract}

Key words: Bicuspid/abnormalities; cone-beam computed tomography; macrodontia; tooth abnormalities/complications; tooth unerupted/surgery

- 1 Department of Pediatric Dentistry, Faculty of Dentistry, Hacettepe University, Ankara, TURKIYE

2 Staff Paediatric Dentist, Tepebasi Dental Center, Ankara, TURKIYE

3 Department of Oral Surgery, Faculty of Dentistry, Hacettepe University, Ankara, TURKIYE

- Corresponding author: Dr. Zafer C. Cehreli Department of Pediatric Dentistry, Faculty of Dentistry, Hacettepe University, Sihhiye 06100 Ankara, TURKIYE Tel: +903123052289

Fax: +903123243190

Email: zcehreliagmail.com

\section{INTRODUCTION}

Macrodontia (megadontia, megalodontia, macrodontism), is a rare shape anomaly that has been used to describe dental gigantism. ${ }^{1}$ Macrodontia is usually associated with systemic disturbances or syndromes such as insulin-resistant diabetes, ${ }^{2}$ otodental syndrome, ${ }^{3,4}$ facial hemihyperplasia, ${ }^{5,6} \quad$ KBG syndrome, ${ }^{7}$ Ekman-Westborg-Julin syndrome, ${ }^{8}$ and $47, X Y Y$ syndrome. ${ }^{9}$ Isolated form of macrodontia has been rarely reported. ${ }^{10-13}$ The 
prevalence of macrodont permanent teeth is 0.03 $1.9 \%,{ }^{14-16}$ with a higher frequency in males. ${ }^{15,16}$ The pathogenetic mechanism underlying macrodontia is still unknown.

Macrodontia can be differentiated into "true generalized," "relative generalized," and "isolated" forms. ${ }^{17}$ In true generalized macrodontia, all teeth are larger than normal, and the condition may be associated with pituitary gigantism. ${ }^{18}$ Relative-generalized macrodontia refers to the presence of normal or slightly larger teeth in smaller jaws. ${ }^{19}$ Isolated macrodontia refers to macrodontia of single teeth, and is an extremely rare condition that may be seen as a simple enlargement of all tooth-related structures ${ }^{20,21}$ or may be related with morphological anomalies. ${ }^{12,22,23}$ This type of macrodontia is more frequently found in incisors and canines, ${ }^{24}$ and has been rarely reported to involve premolars and molars. In particular, macrodontia of premolars is extremely rare and may be confused with fusion or gemination of adjacent teeth to form a single tooth. To date, only 8 cases of isolated macrodontia of second premolars have been reported in the literature; 5 of which have shown bilateral occurrence (Table 1).
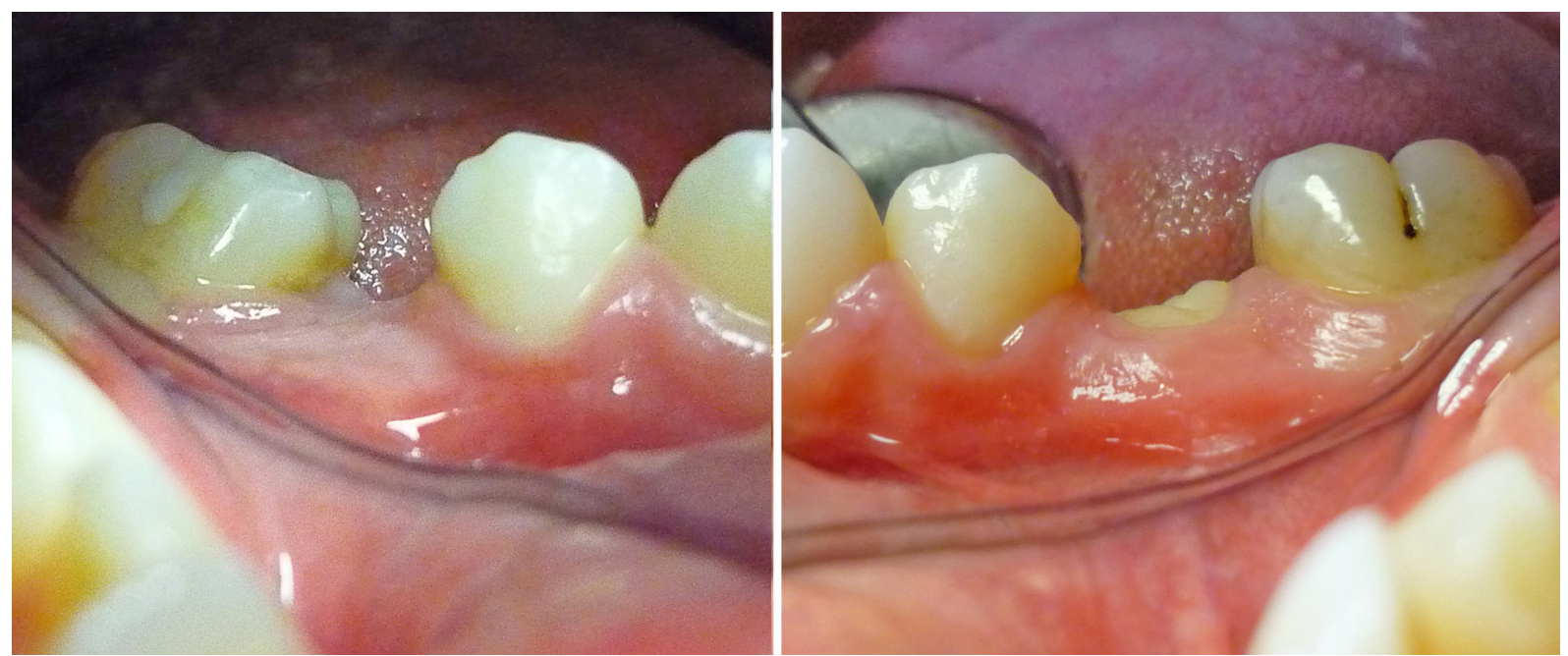

Figure 1. View of the premolar regions from both sides.

Table 1. Summary of published case reports of macrodontia of the mandibular second premolars

\begin{tabular}{lccc|}
\hline Author & Year & Sides Affected & Eruption Status \\
\hline Primack & 1967 & Bilateral & Unerupted \\
Hermel et al & 1968 & Bilateral & Erupted \\
Ekman-Westborg et al & 1974 & Bilateral & Left Erupted, Right Unerupted \\
Reichart et al & 1977 & Unilateral & Unerupted \\
Peck et al & 1983 & Bilateral & Unerupted \\
Groper & 1987 & Unilateral & Unerupted \\
Dugmore & 2001 & Bilateral & Erupted \\
Rootkin-Gray et al & 2001 & Unilateral & Unerupted \\
\hline
\end{tabular}

Depending on their size and morphology, macrodonts can create a variety of functional and esthetic problems that may require endodontic, prosthetic, surgical, and/or orthodontic treatment. ${ }^{12,14,18,23}$ This case report presents clinical and radiographic findings of isolated bilateral macrodontia of mandibular second premolars.

\section{CASE REPORT}

A healthy 12-year-old girl was referred to the Department of Pediatric Dentistry for consultation concerning local crowding associated with macrodontia. The patient's medical history was unremarkable, and there was no family history of any genetic or dental anomalies. Reportedly, the child had not experienced any trauma related to the jaws. The patient was in the late mixed-dentition stage and had Angle class-III molar relationship. The mandibular and maxillary primary second molars had exfoliated and a large mandibular left second premolar was attempting to erupt between the normal-sized first premolar and the first molar teeth (Figure 1).

Radiographic examination of the jaws revealed the presence of mandibular second premolars 
of abnormal size and morphology (Figure 2). The right premolar was distally impacted and its largesized, multitubercular crown was in contact with the mesial root of the first molar (Figure 2). The conical root was in close proximity to the inferior alveolar canal and had a large, single root canal space (Figure 2). The left premolar was partially impacted and showed similar crown and root canal morphology (Figure 2).

Following orthodontic assessment, the patient was scheduled for surgical removal of the macrodont premolars to prevent any possible complications of eruption as well as preparation for consequent orthodontic therapy. Owing to the abnormal angulation of both the premolars, $0.3 \mathrm{~mm}$-thick tomograms were obtained on an ILUMA conebeam computed tomography (CBCT) scanner (Im- tec Corp., Ardmore, OK, USAl to determine their exact position in the vertical and horizontal planes, and thus, facilitate surgical removal with minimal or no damage to neighboring teeth and anatomic structures (Figure 3). The tomograms precisely indicated that the crown of the right macrodont premolar was aligned lingually and was in very close proximity to the root of the first premolar. Both the 2- and 3-dimensional tomographic images confirmed that the second premolars had multitubercular crowns and single conical roots with a large, single root canal space (Figure 3 ).

The teeth were surgically removed in 2 consecutive sessions under local anesthesia. Both teeth were sectioned at the cervical level before elevation due to abnormal dimension of the tooth crowns (Figure 4). Healing was uneventful in both
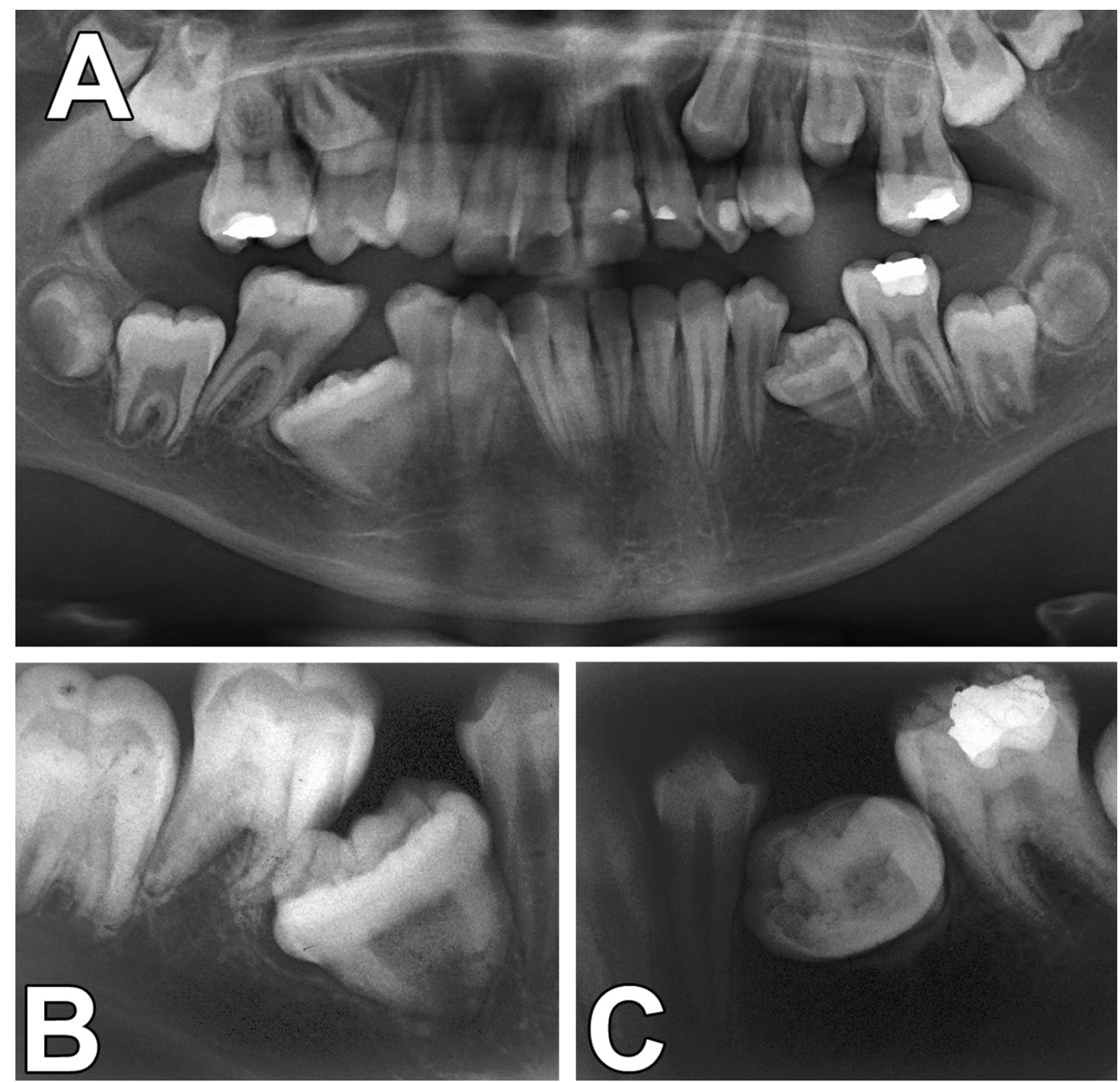

Figure 2. A. Panoramic radiograph showing macrodont mandibular second premolars. B and C. Periapical radiographs of the right and left premolars, respectively. 
the cases. The crowns of the extracted premolars measured $15.3 \mathrm{~mm}$ (right) and $13.16 \mathrm{~mm}$ (left) mesiodistally, and $10.7 \mathrm{~mm}$ (right) and $10.5 \mathrm{~mm}$ (left) buccolingually. After 2 months, fixed appliance therapy was initiated by the orthodontist to correct malocclusion.

\section{DISCUSSION}

Being an extremely rare condition, ${ }^{13}$ macrodontia of mandibular second premolars has been reported exclusively in children (8-14 years) with only 1 exception. ${ }^{8}$ Indeed, disturbances with the eruption of macrodont second premolars and concomitant disruption of developing occlusion or alveolar/gingival enlargement become evident before or between the ages of 11 and 12, when the eruption of mandibular second premolars usually occurs. ${ }^{10}$ Thus, any intervention should be completed before maturity, and, in light of previous re-
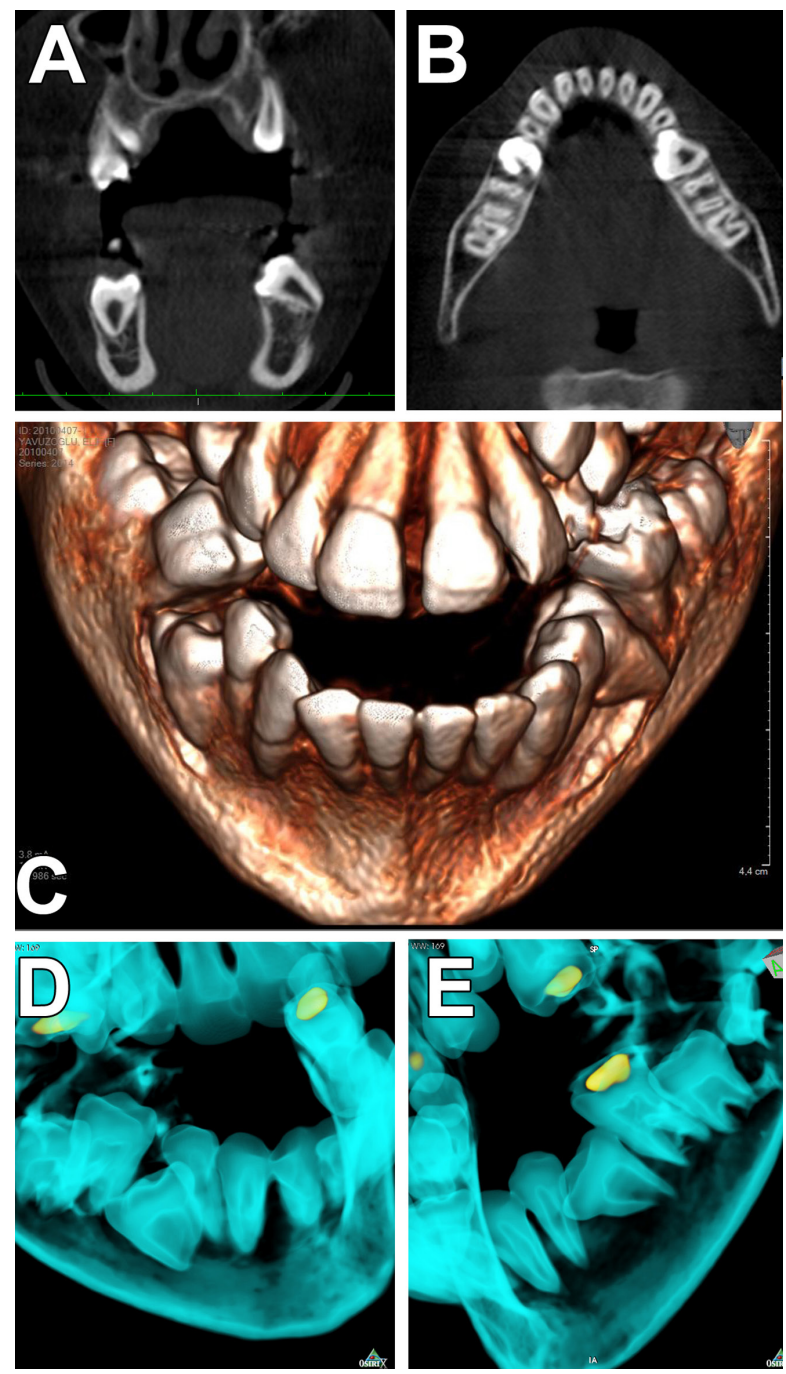

Figure 3. Cone beam CT scans of the macrodont premolars: A. Frontal view, B. Horizontal view. 3D tomograms of the jaws (C), and the right (D) and left (E) macrodont premolars, showing their position, size and morphology. ports, extraction appears to be the only available intervention. ${ }^{10,12,13}$ Following extraction, orthodontic treatment should be started in a timely manner due to disturbances in the arch and occlusion after surgical intervention. ${ }^{12,18}$

The interpretation of conventional radiographs is dependent on the clinician's appreciation as well as his/her knowledge and experience in assessing 2-dimensional images. Radiographic images may fail to locate accurately some anomalies relative to neighboring teeth because of superimposition of adjacent structures. In the present case, the conventional radiographs provided insufficient information to diagnose accurately the location of the macrodont premolars in the vertical and horizontal plane, as well as their exact relationship to the neighboring teeth and inferior alveolar verve. Supplementing plain view radiography with CBCT demonstrated great usefulness in showing the 3-dimensional orientation of impacted premolars within the alveolus, while allowing for detailed, non-destructive investigation of tooth morphology. The additional dose to the patient from the CBCT investigation can be justified by the present case; the information gained was of clear benefit in planning the surgical technique, particularly, in the macrodont left premolar.

Multituberculism has been reported previously in combination with macrodontia and other morphologic anomalies involving the entire dentition. ${ }^{25}$ Consistent with the present case and previous publications, isolated macrodont premolar teeth are also present in multituberculism. ${ }^{10,12,13}$ In most cases, a fine pulpal extension has been shown in the dentinal core at the cusp. Invagination could be either the result of active proliferation of an area of the enamel organ with infolding of the proliferating cells into the dental papilla, or of displacement of a part of the enamel organ into the papilla as a result of abnormal pressure from the surrounding tissue. ${ }^{26}$ Based on the stark similarities in morphology of the isolated macrodont second premolars reported previously, Dugmore10 proposed using the term "macrodont molariform premolars."

\section{CONCLUSION}

Isolated bilateral macrodontia of the mandibular second premolars is an extremely rare dental anomaly, which requires a multidisciplinary-treatment approach along with advanced radiographic assessment. 


\section{REFERENCES}

1. Shafer WG, Hine MK, Levy BM. A textbook of oral pathology. Philadelphia: WB Saunders, 1974.

2. Holmes J, Tanner MS. Premature eruption and macrodontia associated with insulin resistant diabetes and pineal hyperplasia. Report of two cases. Br Dent J 1976;141:280-284.

3. Jorgenson RJ, Marsh SJ, Farrington FH. Otodental dysplasia. Birth Defects Orig Artic Ser 1975;11:115-119.

4. Van Doorne L, Wackens G, De Maeseneer M, Deron P. Otodental syndrome. A case report. Int J Oral Maxillofac Surg 1998;27:121-124.

5. MacMillan AR, Oliver AJ, Reade PC, Marshall DR. Regional macrodontia and regional bony enlargement associated with congenital infiltrating lipomatosis of the face presenting as unilateral facial hyperplasia. Brief review and case report. Int J Oral Maxillofac Surg 1990;19:283-286.

6. Rowe NH. Hemifacial hypertrophy. Review of the literature and addition of four cases. Oral Surg Oral Med Oral Pathol 1962;15:572-587.

7. Herrmann J, Pallister PD, Tiddy W, Opitz JM. The KBG syndrome-a syndrome of short stature, characteristic facies, mental retardation, macrodontia and skeletal anomalies. Birth Defects Orig Artic Ser 1975;11:7-18.

8. Ekman-Westborg B, Julin P. Multiple anomalies in dental morphology: macrodontia, multituberculism, central cusps, and pulp invaginations. Report of a case. Oral Surg Oral Med Oral Pathol 1974;38:217-222.

9. Alvesalo L, Osborne RH, Kari M. The 47,XYY male, Y chromosome, and tooth size. Am J Hum Genet 1975;27:53-61.

10. Dugmore CR. Bilateral macrodontia of mandibular second premolars: a case report. Int J Paediatr Dent 2001;11:69-73.

11. Namdar F, Atasu M. Macrodontia in association with a contrasting character microdontia. J Clin Pediatr Dent 1999;23:271-274.

12. Reichart PA, Westergaard J, Jensen KA. Macrodontia of a mandibular premolar. Oral Surg Oral Med Oral Pathol 1977;44:606-609.

13. Rootkin-Gray VF, Sheehy EC. Macrodontia of a mandibular second premolar: a case report. ASDC J Dent Child 2001;68:347-349, 302.

14. Altug-Atac AT, Erdem D. Prevalence and distribution of dental anomalies in orthodontic patients. Am J Orthod Dentofacial Orthop 2007;131:510-514.

15. Brook AH. A unifying aetiological explanation for anomalies of human tooth number and size. Arch Oral Biol 1984;29:373-378

16. Ooshima T, Ishida R, Mishima K, Sobue S. The prevalence of developmental anomalies of teeth and their association with tooth size in the primary and permanent dentitions of 1650 Japanese children. Int J Paediatr Dent 1996;6:87-94.
17. Shafer WG, Hine MK, Levy BM. A textbook of oral pathology. 4th ed. Philadelphia: WB Saunders, 1983.

18. Groper JN. Macrodontia of a single tooth: review of literature and report of case. J Am Dent Assoc 1987;114:69.

19. Nemes JA, Alberth M. The Ekman-Westborg and Julin trait: report of a case. Oral Surg Oral Med Oral Pathol Oral Radiol Endod 2006;102:659-662.

20. Lupton JR, Crandell CE. Macrodontia: a case report. J North Car Dent Soc 1962;46:10-12.

21. Primack JE. Individual bilateral megadontism: report of case. J Am Dent Assoc 1967;75:655-657.

22. Gibson AC. Bilateral macrodontism of mandibular third molars with impaction of second molars. Oral Surg Oral Med Oral Pathol 1970;29:717.

23. Peck S, Peck H, Phaneuf RA. Megadontism anomaly of the mandibular second premolars. Oral Surg Oral Med Oral Pathol 1983;55:543.

24. Colby RA, Kerr DA, Robinson HBG. Color atlas of oral pathology. 2nd ed. London: Pitman medical, 1961.

25. Robbins IM, Keene HJ. Multiple Morphologic Dental Anomalies. Report of a Case. Oral Surg Oral Med Oral Pathol 1964;17:683-690.

26. Reichart PA, Metah D, Sukasem M. Morphologic findings in dens evaginatus. Int J Oral Surg 1982;11:59-63. 